\title{
Water Absorption and Thickness Swelling Characterization of Chicken Feather Fiber and Extracted Fish Residue Powder Filled Epoxy Based Hybrid Biocomposite
}

\author{
Gagan Bansal ${ }^{\star *}$, Singh VK ${ }^{2}$ Patil PP ${ }^{3}$ and Shweta Rastogi ${ }^{4}$ \\ ${ }^{1}$ Graphic Era University, Dehradun, India \\ ${ }^{2}$ G. B. Pant University of Agriculture and Technology, Pantnagar, India \\ ${ }^{3} \mathrm{ME}$ Department, Graphic Era University, Dehradun, India \\ ${ }^{4}$ Teerthankar Mahavir University, Moradabad, India
}

\begin{abstract}
Excellent compatibility characteristics of CY-230 epoxy resin with a large variety of fibers and elemental particulates has lead us to develop the cost effective materials with desired characteristics. In the current investigation the livestock waste i.e. Chicken Feather Fiber (CFF) and extracted Fish residue is used as reinforcing materials. Here, the physical appearance, weight density, thickness swelling and water absorption characteristics of the chicken feather fiber filled epoxy based composite is scrutinized. The best CFF-epoxy composition is diagnosed which was $5 \mathrm{wt} \%$ CFF in epoxy resin and hardener filled composite. Results obtained correlates that the maximum water absorption at $4 \mathrm{wt} \%$ of CFF (i.e. $1.49 \%$ ) was due to the maximum volume fraction $(3.62 \%$ ) at the $4 \mathrm{wt} \% \mathrm{CFF}$ based composition. The improvement was characterized at $5 \mathrm{wt} \%$ CFF composition. Later the hybrid composition was fabricated with varying percentage of Extracted residue powder (ERP) from Rohu fish waste. Similarly all other results were characterizes and interpreted. The optimum hybrid composition having most compatible CFF and ERP weight percentage in Epoxy based hybrid composite was thus concluded.
\end{abstract}

Keywords: Biocomposite; Water absorption; Livestock; Thickness swelling; Epoxy resin; Chicken feather fiber

\section{Introduction}

Epoxy resin may be defined as the polymer in which chain extension and cross linking occurs through epoxy group reactions $[1,2]$. The livestock waste i.e. CFF were appreciated because billions of kilograms of waste feathers are engendered each year by poultry processing plants, creating a stark solid waste disposal concern [3]. Chicken feathers are roughly $91 \%$ protein (keratin), $1 \%$ lipids and $8 \%$ water. In the current research work, the hybrid biocomposite is fabricated using epoxy resin (CY-230) as matrix with hardener (HY951) as curing agent, reinforced with varying weight percentages (wt\%) of chicken feather fiber (CFF) and later extracted residue powder (ERP) from Rohu fish is used as Particulate to enhance the physical properties of developed composite. Composite materials with their high strength to weight ratio and their diverse functionalities have attracted most of the researchers towards the advanced study of the hybrid composites.

Epoxy resin was discovered in 1909 [4]. Ciba-Geigy Ltd. in 1946 first introduced epoxy resins [5]. Epoxy resins are the thermoset plastic resin which has wide application in the polymer composite domain. These resins are synthesized by condensation of bisphenol A. Epoxy resin CY-230 has negligible shrinkage, excellent resistance to chemical attack, non-appearance of volatiles on curing, outstanding electrical insulating properties. In general epoxy resin exhibits CFF better surface properties, good wetting ability and shows immense characteristics at elevated temperatures.

The foremost need that occurred for the fabrication of hybrid biocomposite was to reduce the void contents, increase the molecular bonding and surface characteristics of the chicken feather filled composite. Adding ERP that constitutes of silica, calcium, sodium etc. has facilitated the author to introduce it as a particulate material in the current research work. Also the results obtained after casting the hybrid composite has proven the decision right and we obtained the improved material.

\section{Materials and Methods}

The fabricating of composite utilizes the epoxy resin CY-230 as the matrix material, CFF as the reinforcing fiber, hardener HY-951 as a curing agent and further Extracted residue powder from Rohu fish as the particulate for hybridizing the CFF filled biocomposite (Figure 1). Also, the hand lay-up technique is employed for the development of composite.

\section{Epoxy resin (CY-230)}

Epoxy resin CY-230 is a polymeric chain of Bisphenol A (Figure 2) cured with triethylenetetraamine (TETA) as a hardener. It is a thermosetting polymer that has great compatibility with the large variety of fibers. It has good thermal stability and fire retardation characteristics. Araldite CY-230 is a liquid solvent free epoxy resin. Epoxy resin has a wide range of industrial applications because of their high strength and mechanical adhesiveness characteristic. It can be easily colored.

\section{Hardener (HY-951)}

HY-951 hardener has maximum affinity with epoxy resin. It is yellowish color liquid composed of the aliphatic amine group. In the current investigation 10 weight percentage of hardener was used for curing epoxy resin based composite as suggested and recommended by Singh et al. [6].

*Corresponding author: Bansal G, Assistant Professor, Graphic Era University Dehradun, India, Tel: +91-9897055488; E-mail: gaganbansal12345@gmail.com

Received July 19, 2016; Accepted July 25, 2016; Published August 01, 2016

Citation: Bansal G, Singh VK, Patil PP, Rastogi S (2016) Water Absorption and Thickness Swelling Characterization of Chicken Feather Fiber and Extracted Fish Residue Powder Filled Epoxy Based Hybrid Biocomposite. Int J Waste Resour 6: 237. doi: $10.4172 / 2252-5211.1000237$

Copyright: $\odot 2016$ Bansal G, et al. This is an open-access article distributed under the terms of the Creative Commons Attribution License, which permits unrestricted use, distribution, and reproduction in any medium, provided the original author and source are credited. 


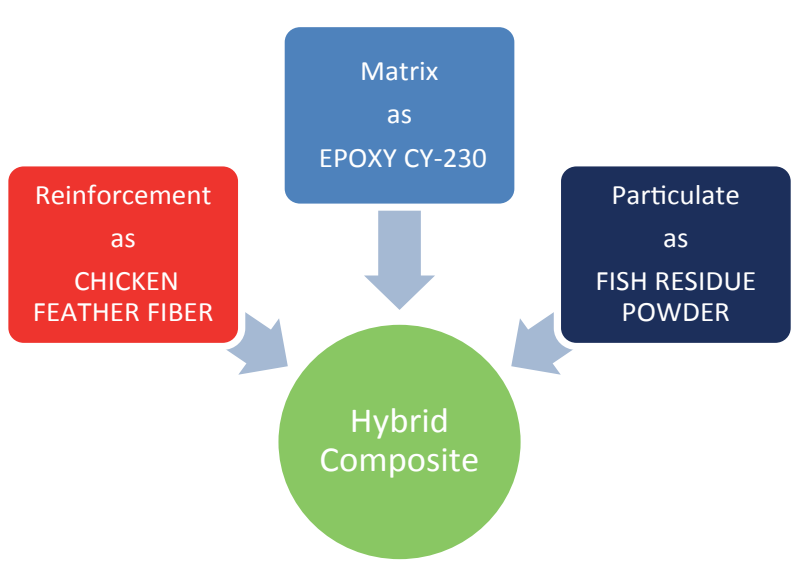

Figure 1: Constituents in hybrid composite.

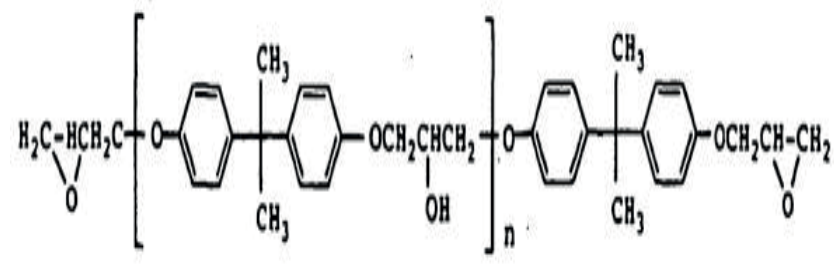

Figure 2: Chemical structure of Bisphenol-A based epoxy resin.

\section{Chicken feather fiber}

Chicken Feathers are the waste product from the processing of chickens for food. Chicken feather initiates from free renewable livestock biowaste. Chicken feather is approximately $91 \%$ keratin, $8 \%$ water and $1 \%$ lipids by mass. Both the fiber and quill consist of hydrophobic keratin that's why CFF shows irregular surface finish during composite fabrication. There are five generally recognized categories of feathers: contour, bristle, semiplume, down and filoplume as shown in Figure 3.

\section{Extracted residue powder from rohu fish}

ERP is the white colored micro sized particle which was extracted from the Rohu fish. The various laboratory reactions were performed in the development of ERP. The developed ERP contains varying percentages of elements like calcium, sodium, and oxygen etc. in compound form which shows better compatibility with epoxy. The micro and nano sized elements present in the ERP was diagnosed using field emission scanning electron microscopy (FE-SEM) test.

\section{Silica gel grease}

It is a jelly type semi solid paste that provides ease in demoulding the final casting from the mould in order to achieve the defect free and good surface finished final casting. Silica gel acts as an intermediate layer between the mould and the poured liquid mixture used for fabricating the composite. it restricts direct contact between the composite material and the mould.

\section{Method of casting}

'Initially, we require CFF, epoxy resin (CY-230), hardener (HY951), steel mould, thermometer, the convection oven, silica gel grease,
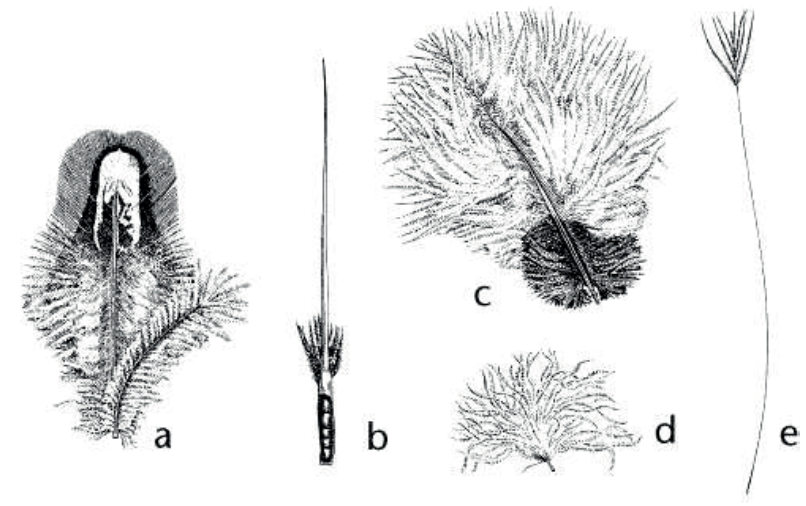

Figure 3: Five primary types of chicken feathers: (a) contour, (b) bristle (c) semi plume (d) down (e) filo plume.

$\mathrm{NaOH}$ solution, extracted silica powder, Weight measuring machine, measuring beakers and stirrer. The solution obtained by mixing chicken feather fiber in epoxy resin is kept in the oven at a temperature of $140^{\circ} \mathrm{C}$ for one hour as per the recommendation of Singh and Gope [7]. Allow the mixture to cool back to $40^{\circ} \mathrm{C}$ in an open atmosphere. Add $10 \mathrm{wt} \%$ of hardener and using hand layup technique pour the mixture in the steel mould and keep it undisturbed for 48 hours (Figure 4). After 48 hours demould the casting and perform post curing for at least 7 days in order to improve the strength and surface properties of casting and then based on ISO standards make proper specimen for characterization.

Later to cast the hybrid biocomposite the varying weight percentages of ERP is also added with the CFF and epoxy and then kept for heating at $140^{\circ} \mathrm{C}$.

In the current research work $5 \mathrm{wt} \%$ of CFF is considered as the optimum composition for developing hybrid biocomposite with varying weight percentage of ERP from fish as particulate. The assumption is based on the overall characterization of CFF filled epoxy based composite (Tables 1 and 2).

\section{Results and Discussion}

\section{Density test}

Density can be defined as an intensive property of the material which is termed as the ratio of mass of the body to the volume of the body.

i.e. Density $=($ Mass of the Body $) /($ Volume of the Body $)$

Its SI unit is $\mathrm{kg} / \mathrm{m}^{3}$

It is denoted by the symbol " $\rho$ " (pronounced as roh)

Through the existing literature reviews it was noticed that the approximate density of Epoxy resin (CY-230) with hardener (HY-951) is $1150 \mathrm{~kg} / \mathrm{m}^{3}$, ash powder is $2130 \mathrm{~kg} / \mathrm{m}^{3}$ and Chicken feather is 800 $\mathrm{kg} / \mathrm{m}^{3}$.

The theoretical density of composite samples in terms of weight fraction can be obtained easily by the following equations suggested by Agarwal, B.D. and Broutman.

$$
\rho_{\mathrm{u}}=\frac{1}{\left(\frac{\mathrm{W}_{\mathrm{f}}}{\rho_{\mathrm{f}}}\right)+\left(\frac{\mathrm{W}_{\mathrm{m}}}{\rho_{\mathrm{m}}}\right)}
$$


Citation: Bansal G, Singh VK, Patil PP, Rastogi S (2016) Water Absorption and Thickness Swelling Characterization of Chicken Feather Fiber and Extracted Fish Residue Powder Filled Epoxy Based Hybrid Biocomposite. Int J Waste Resour 6: 237. doi:10.4172/2252-5211.1000237

Page 3 of 6

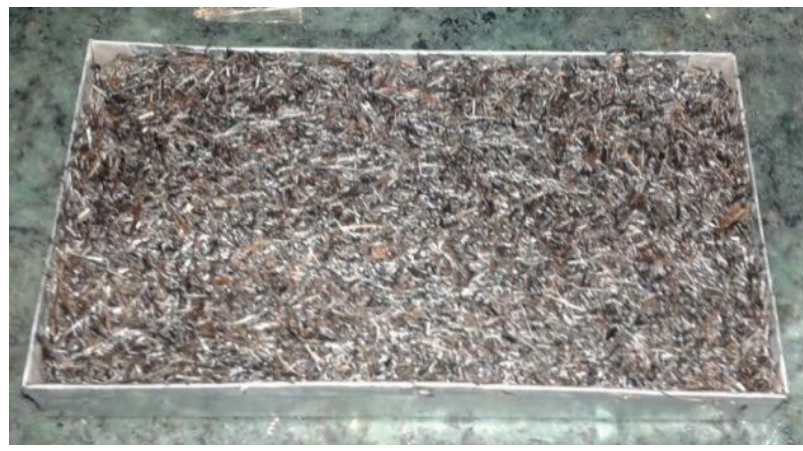

Figure 4: Prepared casting kept for solidification.

\begin{tabular}{|c|c|c|c|}
\hline Designation & $\begin{array}{c}\text { Epoxy resin } \\
\text { (grams) }\end{array}$ & $\begin{array}{c}\text { Hardener } \\
\text { (grams) }\end{array}$ & $\begin{array}{c}\text { CFF } \\
\text { (grams) }\end{array}$ \\
\hline CONTROL & 230 & 23 & 0.00 \\
\hline CFF 1 & 230 & 23 & 2.53 \\
\hline CFF 2 & 230 & 23 & 5.06 \\
\hline CFF 3 & 230 & 23 & 7.59 \\
\hline CFF 4 & 230 & 23 & 10.12 \\
\hline CFF 5 & 230 & 23 & 12.65 \\
\hline CFF 6 & 230 & 23 & 15.18 \\
\hline CFF 7 & 230 & 23 & 17.71 \\
\hline
\end{tabular}

Table 1: Design of experiments for CFF filled composite.

\begin{tabular}{|c|c|c|c|c|}
\hline Designation & $\begin{array}{c}\text { Epoxy resin } \\
\text { (grams) }\end{array}$ & $\begin{array}{c}\text { Hardener } \\
\text { (grams) }\end{array}$ & $\begin{array}{c}\text { CFF } \\
\text { (grams) }\end{array}$ & $\begin{array}{c}\text { Extracted Residue } \\
\text { Powder (grams) }\end{array}$ \\
\hline ESP 0 & 230 & 23 & 12.65 & 0.00 \\
\hline ESP 1 & 230 & 23 & 12.65 & 2.66 \\
\hline ESP 2 & 230 & 23 & 12.65 & 5.32 \\
\hline ESP 3 & 230 & 23 & 12.65 & 7.97 \\
\hline ESP 4 & 230 & 23 & 12.65 & 10.62 \\
\hline ESP 5 & 230 & 23 & 12.65 & 13.28 \\
\hline ESP 6 & 230 & 23 & 12.65 & 15.93 \\
\hline
\end{tabular}

Table 2: Design of experiment for extracted fish powder filled hybrid composites.

$$
\rho_{\text {hct }}=\frac{1}{\left(\frac{\mathrm{W}_{\mathrm{f}}}{\rho_{\mathrm{f}}}\right)+\left(\frac{\mathrm{W}_{\mathrm{m}}}{\rho_{\mathrm{m}}}\right)+\left(\frac{\mathrm{W}_{\mathrm{p}}}{\rho_{\mathrm{p}}}\right)}
$$

Where, $W$ and $\rho$ symbolizes the weight fraction and the density respectively. The suffix $c t, h c t, f, m$ and $p$ stands for the composite, hybrid composite, fiber, matrix and particulate respectively.

The actual/experimental density ( $\rho_{c e}$ and $\rho_{\text {hce }}$ ) of the composite or hybrid composite material, however, can be firmed experimentally by the uncomplicated toluene immersion technique. The volume fraction of voids $\left(\mathrm{V}_{v}\right)$ for CFF filled composite and hybrid composite $\left(\mathrm{V}_{\mathrm{hv}}\right)$ is calculated by the help of the subsequent Equations 4 and 5 respectively

$\mathrm{V}_{v}=\frac{\rho_{\mathfrak{d}}-\rho_{\mathrm{e}}}{\rho_{\mathrm{t}}}$

$$
\mathrm{V}_{h v}=\frac{\rho_{\text {hct }}-\rho_{\text {hce }}}{\rho_{\text {hct }}}
$$

Figure 5 shows the continuous decrease in weight density with increasing wt\% of CFF in epoxy and the reason is the inclusion of light weighted chicken fibers in the epoxy. Also the reverse trend was observed in Figure 6 as the ERP weight is comparatively higher than the other constituents of the composite. Therefore with increasing ERP $\mathrm{wt} \%$ the density of hybrid composite was linearly increasing...Volume void fraction (Figure 7) for CFF filled composite and $5 \mathrm{wt} \% \mathrm{CFF}$ along with varying wt $\%$ of ERP is listed in Tables 3 and 4 respectively. The increase in void fraction with increasing wt\% of CFF can be due to the improper mixing between the epoxy and CFF using hand leyup technique. But between 4 to $5 \mathrm{wt} \%$ of CFF the good bonding characteristics can be observed.

Volume void fraction percentages as mentioned in Tables 3 and 4 signifies the effective results as far as current research work is concerned. Figure 7 shows the increasing trend of void fraction with increasing wt\% of CFF in the Epoxy resin which was scrutinized to be due to the casting technique adopted and also the less adhesion characteristics of the CFF also the inclusion of ERP in the fixed CFF (5
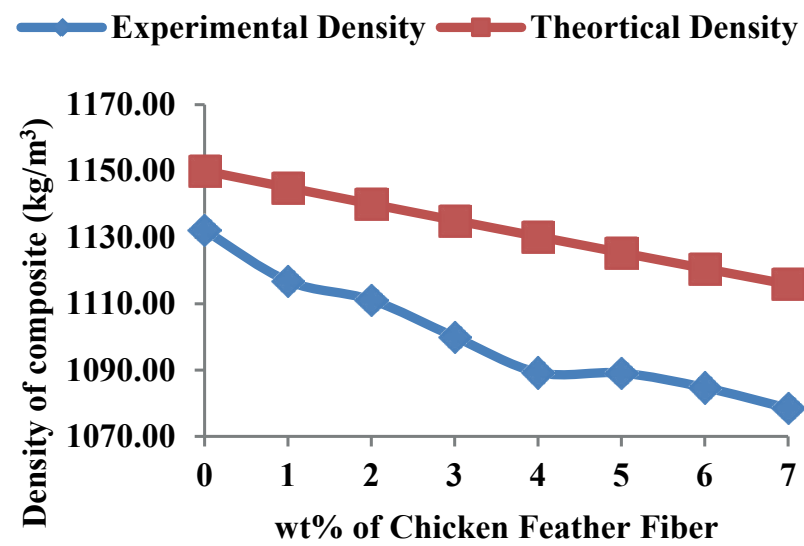

Figure 5: Effect of wt\% of CFF on density of composite.
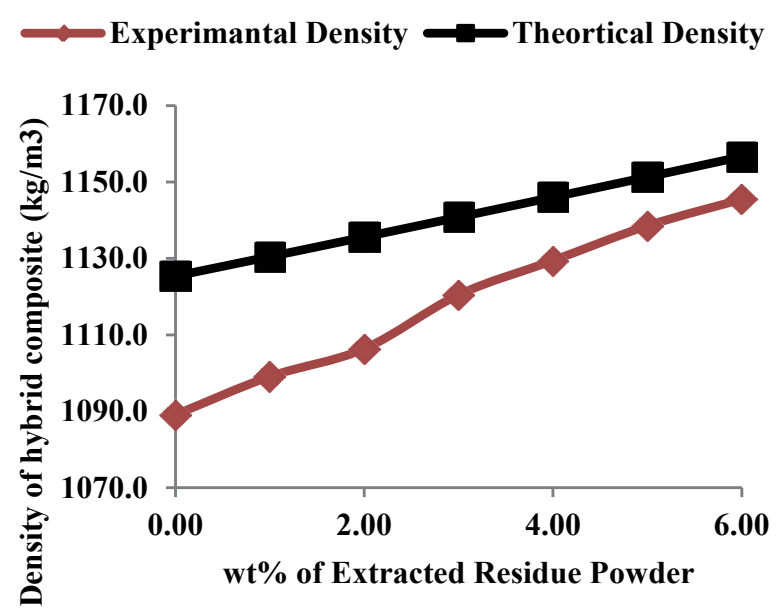

Figure 6: Effect of wt $\%$ of extracted residue powder (in $5 \mathrm{wt} \% \mathrm{CFF}$ ) on density of composite. 

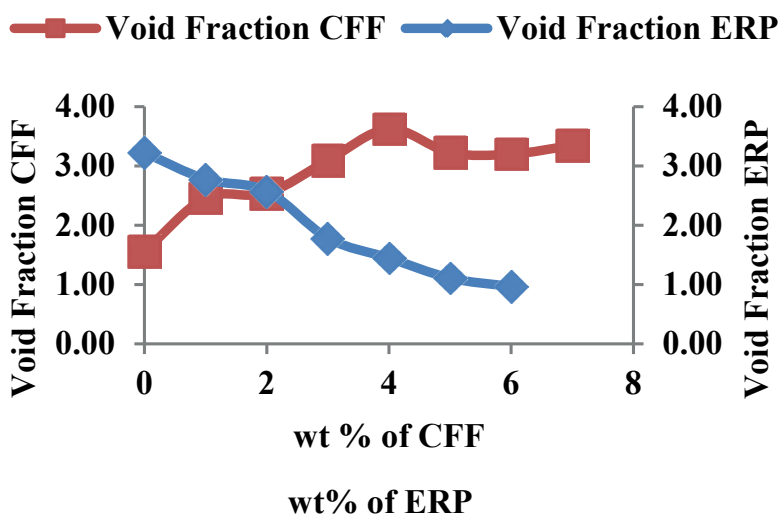

Figure 7: Effect of varying wt\% of CFF/ERP on percentage of volume void fraction.

\begin{tabular}{|c|c|c|c|}
\hline Composition & $\begin{array}{c}\text { Experimental } \\
\text { Density } \\
\mathbf{( k g / \mathbf { m } ^ { 3 } )}\end{array}$ & $\begin{array}{c}\text { Theoretical Density } \\
\mathbf{( \mathbf { k g } / \mathbf { m } ^ { 3 } )}\end{array}$ & $\begin{array}{c}\text { Volume Void Fraction } \\
\mathbf{( \% )}\end{array}$ \\
\hline CFF 0 & 1132.08 & 1150 & 1.56 \\
\hline CFF 1 & 1116.82 & 1144.991 & 2.46 \\
\hline CFF 2 & 1111.11 & 1140.025 & 2.54 \\
\hline CFF 3 & 1100.00 & 1135.102 & 3.09 \\
\hline CFF 4 & 1089.29 & 1130.221 & 3.62 \\
\hline CFF 5 & 1089.12 & 1125.382 & 3.22 \\
\hline CFF 6 & 1084.75 & 1120.585 & 3.20 \\
\hline CFF 7 & 1078.51 & 1115.828 & 3.34 \\
\hline
\end{tabular}

Table 3: Density and volume void fraction percentage for various composition of CFF - epoxy resin composite.

\begin{tabular}{|c|c|c|c|}
\hline Composition & $\begin{array}{c}\text { Experimental } \\
\text { Density } \\
\left(\mathbf{k g} / \mathbf{m}^{3}\right)\end{array}$ & $\begin{array}{l}\text { Theoretical Density } \\
\qquad\left(\mathrm{kg} / \mathrm{m}^{3}\right)\end{array}$ & $\begin{array}{c}\text { Volume Void Fraction } \\
(\%)\end{array}$ \\
\hline ERP 0 & 1089.12 & 1125.38 & 3.22 \\
\hline ERP 1 & 1099.10 & 1130.47 & 2.78 \\
\hline ERP 2 & 1106.36 & 1135.61 & 2.58 \\
\hline ERP 3 & 1120.46 & 1140.79 & 1.78 \\
\hline ERP 4 & 1129.44 & 1146.02 & 1.45 \\
\hline ERP 5 & 1138.53 & 1151.30 & 1.11 \\
\hline ERP 6 & 1145.45 & 1156.63 & 0.97 \\
\hline
\end{tabular}

Table 4: Density and volume void fraction percentage for various compositions of ERP and 5 wt $\%$ CFF filled epoxy resin hybrid composite.

wt\% CFF) composition had led to decrease in the volume void fraction due to the voids filling by micro sized particulate and the enhanced bonding characteristics in hybrid biocomposite. It helps to correlate the thickness swelling and water absorption effect in the prepared samples too.
Figure 8 shows the variation in the amount of water absorption with change in CFF wt\% and it was observed that the water absorption becomes almost stagnant after 30 hours of dipping under water. Figure 9 shows maximum percentage of water absorbed. It was observed that maximum percentage of water absorption was raising till $4 \mathrm{wt} \%$ of CFF in epoxy based composite after that it was decreasing which shows the presence of amount of voids in the casting. Similar trend can be observed in Figure 7. Also very less percentage of water absorption was observed in the composite (i.e. 1.49\% at $4 \mathrm{wt} \% \mathrm{CFF}$ ) that proved the hydrophobic nature of CFF with epoxy resin.

Later in $5 \mathrm{wt} \%$ CFF the varying wt\% of ERP was added and it was seen (Figures 10 and 11) that that when the hybrid samples were kept for 48 hours in water the percentage of water absorption was decreasing with increasing wt $\%$ of ERP as the micro sized ERP was filling the pores and void in the composite also the same observation was made with decreasing Volume void fraction that the voids were decreasing with increasing ERP wt\%.

\section{Thickness swelling test}

Similar to water absorption trend the thickness swelling also showed the increasing trend with increasing wt\% of CFF in epoxy based composite as the water was seems to be filling the voids and intermolecular spaces that rises the linear dimension of the composite (Figures 12 and 13). Pure epoxy has $0.45 \%$ of thickness welling and it rises to maximum of $0.66 \%$ at $7 \mathrm{wt} \%$ CFF which is very negligible rise
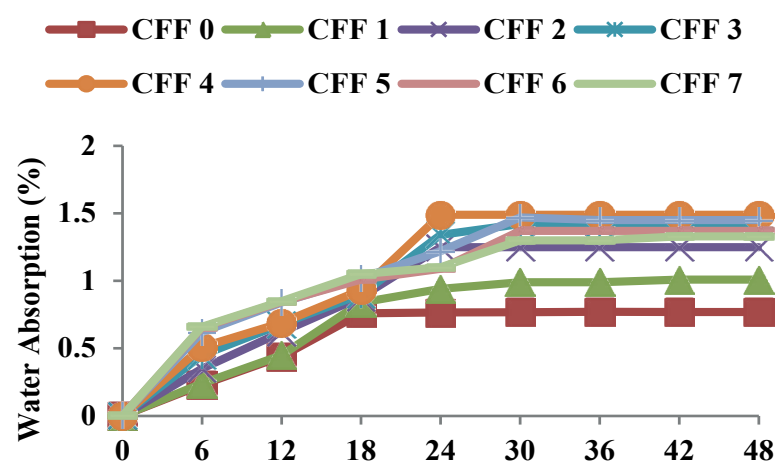

Time Duration (in hours)

Figure 8: Variation in water absorption \% with time for CFF filled composites

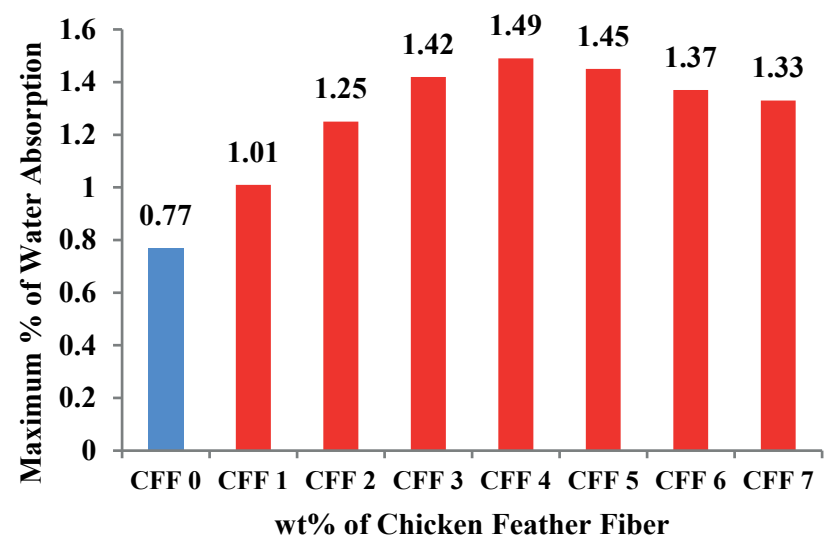

Figure 9: Effect of wt\% of CFF on maximum water absorption. 

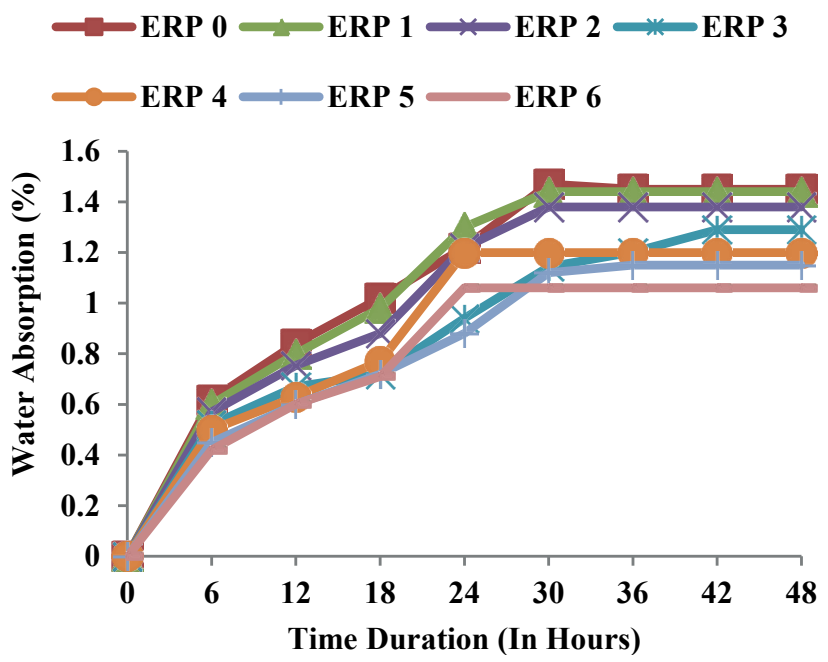

Figure 10: Variation in water absorption \% with time for ERP filled composites.

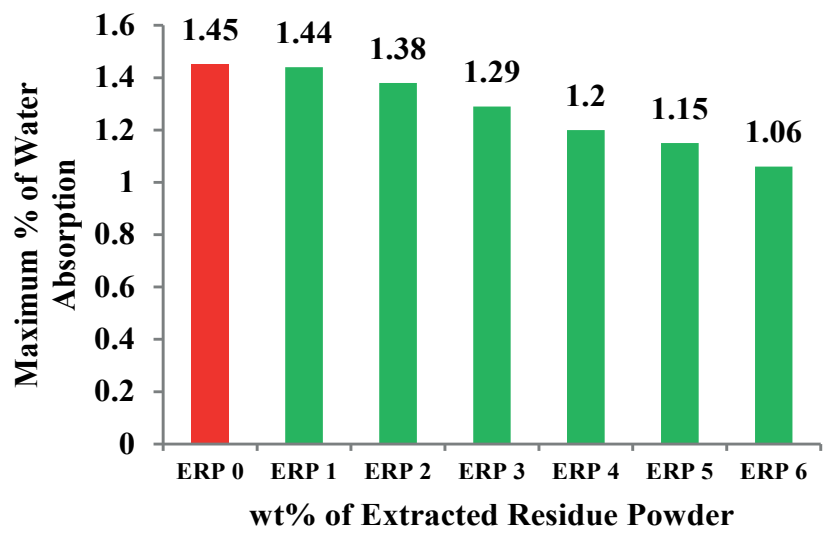

Figure 11: Effect of wt\% of ERP on Maximum Water Absorption.

of $0.21 \%$. Addition of ERP in constant ( $5 \mathrm{wt} \% \mathrm{CFF}$ ) fiber composition the thickness swelling was decreasing and reached minimum to $0.41 \%$ at $6 \mathrm{wt} \%$ ERP (Figures 14 and 15). Decrease in thickness swelling \% of hybrid composite results in better surface properties and hardness as it relates to diminution of surface irregularities and presence of voids on the outer surface of the final casting. The major reason diagnosed for the rise and fall in the thickness swelling is the permissibility of water addition in the material. The random fiber orientation and amorphous structural closed packing also results in the void generation and thickness swelling of the fabricated material. Thus the hybrid composition shows the improved properties and provides better flooring applications.

\section{Conclusions}

The density of CFF filled epoxy based composite was continuously decreasing due to the inclusion of light weighted chicken feather in epoxy resin but the increasing trend was observed while adding ERP for the development of hybrid biocomposite. Also with the rise in wt $\%$ of particulate (extracted residue powder from fish) the density of the hybrid composite rises and it reaches close to density of cured epoxy resin at $3 \mathrm{wt} \%$ of ERP in $5 \mathrm{wt} \%$ CFF filled composite. The void

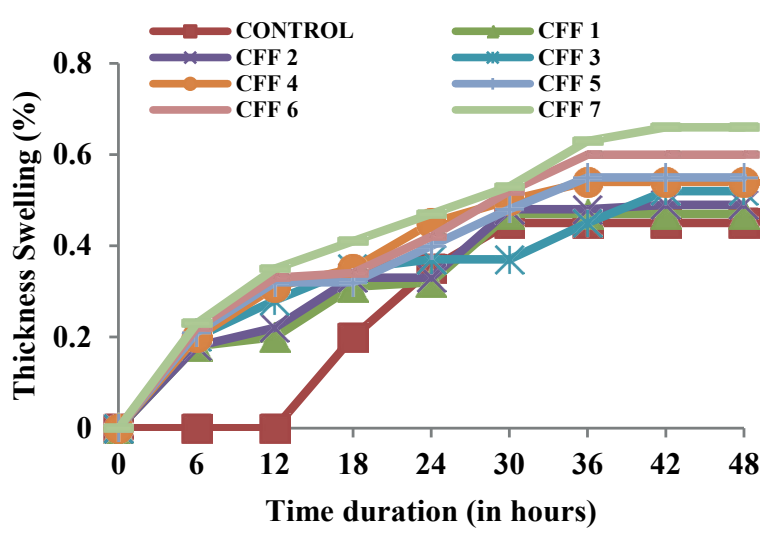

Figure 12: Variation in thickness swelling $\%$ with time for CFF filled composites.

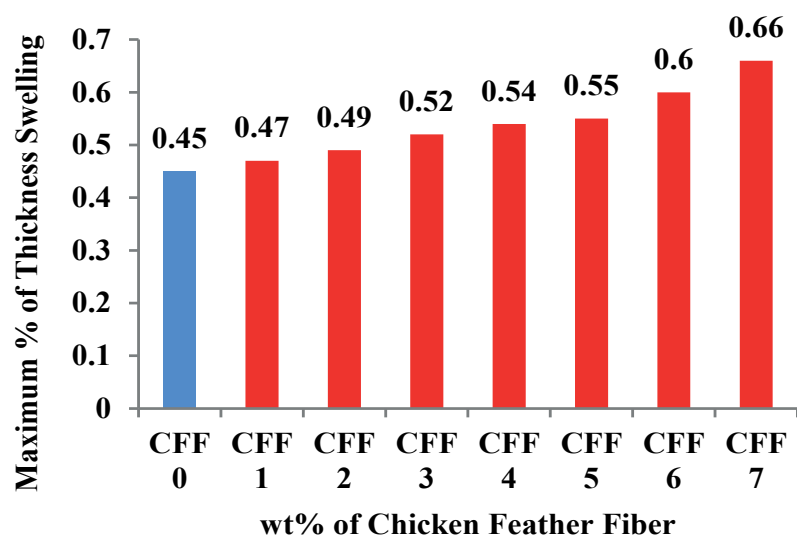

Figure 13: Effect of wt\% of CFF on maximum thickness swelling.
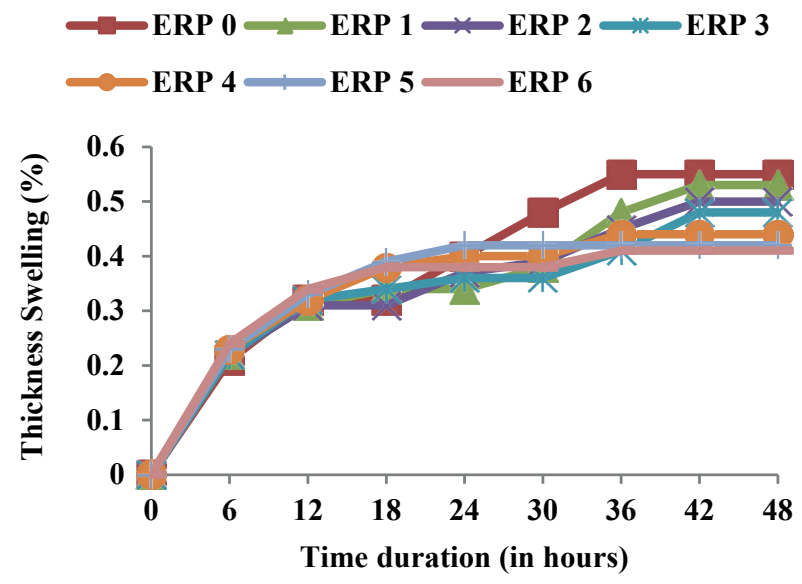

Figure 14: Variation in thickness swelling \% with time for ERP filled hybrid composites.

percentage was improved by hybriding the CFF filled composite.

Water absorption and thickness swelling showed almost the 


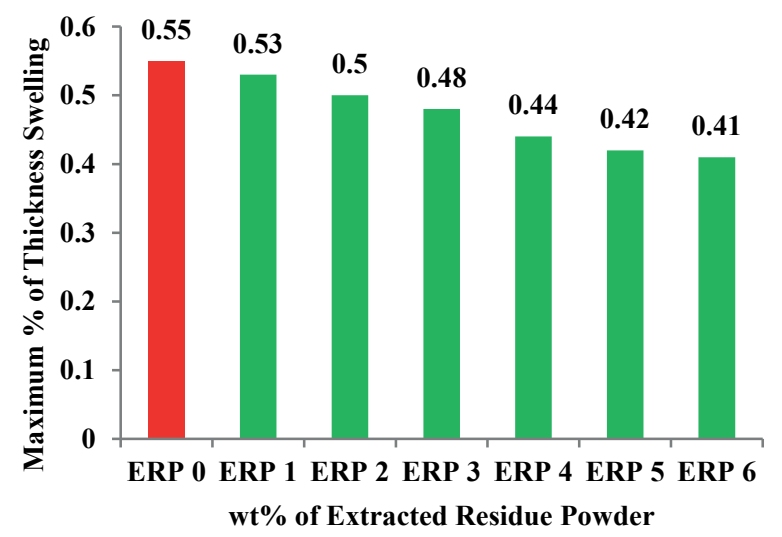

Figure 15: Effect of wt\% of ERP on maximum thickness swelling.

similar fashion of variation with increasing wt $\%$ of CFF and ERP in the developed material and the trend was in contrast with the percentage of void fraction in the material. Water absorption and thickness swelling test revealed that the developed CFF based material has good adhesion fiber-reinforcement bonding on hybrid composite development. The rate of water absorption and thickness swelling becomes almost constant after certain interval of time. Nano sizing of the particulate material can be used for more compact and rigid casting that can further reduce the percentage of water absorption and thickness swelling of the material with similar weight density.

\section{Acknowledgement}

Author wants to sincerely thank Graphic Era University, Dehradun and G. B. Pant University of Agriculture and Technology, Pantnagar for providing all kinds of amenities, funding and infrastructure in the progression of the research work.

\section{References}

1. Gould RF (1970) Epoxy resins (Advances in chemistry series No.92). American Chemical Society, Washington.

2. May CA, Tanaka Y (1973) Epoxy Resin: Chemistry and Technology. Marcel Dekker. New York.

3. Parkinson G (1998) Cheentator: a higher use for lowly chicken feathers. Journa of Chemical Engineering 105: 21-26.

4. May CA (1988) Epoxy Resins, Chemistry and Technology. Marcel Dekker, New York.

5. Nagarjuna RP, Smita M, Nayak SK (2014) Synthesis and Modifications of epoxy Resins and their Composites: A Review. In Taylor and Francis, PolymerPlastics Technology and Engineering 53: 1723-1758.

6. Singh VK, Bansal G, Negi P, Bisht A (2016) Characterization of Flexural and Impact Strength of Jute/Almond Hybrid Biocomposite. Journal of Testing and Evaluation. ASTM International.

7. Singh VK, Gope PC (2010) Silica-Styrene-Butadiene Rubber Filled Hybrid Composites.Experimental Characterization and Modeling. Journal of Reinforced Plastics and Composites 29: 2450-2468. 